\title{
Dimensional Joint Running-in of Cylindrical Parts of Mining Machinery
}

\author{
Valeriy Blumenstein ${ }^{1, *}$, Andrey Krechetov ${ }^{1}$, Maksim Mahalov $^{1}$, and Oleg Ostanin ${ }^{1}$ \\ ${ }^{1}$ T.F. Gorbachev Kuzbass State Technical University, 650000 Kemerovo, 28, Vesennaya st., the \\ Russian Federation
}

\begin{abstract}
The current task of engineering is to ensure the quality and reliability of critical parts of an extended cylindrical shape. This task is especially relevant in the production of power hydraulics parts for mining equipment (ME). One of the ways to ensure the required quality of the surface layer (SL) of mining equipment parts is the use of combined and joint methods of parts hardening by surface plastic deformation (SPD). Combined methods present sequential machining in which the methods used are separated into different technological steps, while the joint machining is carried out by concentrating the methods into one technological step (setup). The analysis shows that this approach, although it has a number of indisputable advantages, allowing an increase in the accuracy, machining efficiency and SL quality, is not without drawbacks that hinder the use of combined and joint machining methods in the manufacture of parts with IT 8-9 accuracy. The dimensional joint runningin method (DJR) is based on the original scheme of interaction between the cutting and deforming tools allowing a cylindrical surface with an accuracy of IT 8-9 and a roughness of no more than Ra $0.4 \mu \mathrm{m}$, hardened to a depth of $10 \mathrm{~mm}$ in one pass. The study shows the possibilities of a much greater SL deformation without its destruction than with the traditional SPD. The analysis of the structure and basic technologies has shown the feasibility of replacing a number of turning and grinding operations with one dimensional joint running-in operation. The design of the device for DJR based on a lathe is given. The completed economic calculations have established that it is possible to implement this method in the existing economic situation.
\end{abstract}

\section{Introduction}

Kuzbass is the largest coal region in Russia, where up to $50 \%$ of all coal production is carried out underground using mechanized complexes. The main units of powered mine supports are power hydraulic cylinders; in this market segment, imported products prevail, which surpass domestic analogues in a number of technical characteristics. The analysis has shown that about $70 \%$ of hydraulic cylinder failures are due to seal failure and leakage due to intense wear, $24 \%$ due to bending of the connecting rods, $45 \%$ due to the formation of scoring on the working surfaces of the connecting rods and sleeves, $1.5 \%$ due to damage to pistons and lugs. Moreover, the declared warranty period of hydraulic cylinders, which are

* Corresponding author: blumenstein.vu@gmail.com 
manufactured by many domestic and foreign companies, does not exceed 12 months. In addition to the above reasons of equipment failure, there are factors that affect the quality of the surface layer of hydraulic cylinder rods, its reliability and durability. These factors are divided into three groups: technological, operational and constructive accounting in average for $26 \%, 47 \%$ and $27 \%$ of failures, respectively.

In particular, Kuzbass machine plants manufacture rods from chrome-plated finished rolled tubular products. In turn, in metallurgical plants, in the production of chrome-coated rolled tubular products, the initial rolled products are used with large machining allowances in order to ensure the required accuracy and quality for application of this electroplated coating. Moreover, if the initial rolled products have an accuracy of IT 14-15, then 4-6 machining passes are required to remove allowances of the order of 5-8 $\mathrm{mm}$ per side to obtain accuracy within the order of IT 8-9. In the process of rods repairing, a significant part of allowances is removed from the surface after applying a new layer to replace the worn one.

The analysis showed that the use of modern effective technological processes for manufacturing parts of power hydraulics ensures an increase in the reliability of mining equipment, reduction of material costs in the manufacturing and repair processes.

One of the ways to ensure the required quality of the surface layer (SL) is the use of combined and joint methods of parts hardening by surface plastic deformation (SPD). Combined methods present sequential machining, in which the methods used are separated into different technological steps, which makes it possible to set a separate machining mode for each tool. Joint machining methods are implemented by concentrating the methods into one technological step (setup), thus reducing machine time and significantly increasing labor productivity.

Both domestic and foreign researchers [1-7] are actively involved in development and study of the methods of combined and joint machining.

SPDs are joined and combined in many ways: by passing an electric current through the contact zone, applying a magnetic field, leading cutting, applying a chemical or electrochemical coating, abrasive-diamond machining, applying ultrasonic vibrations, SL heating, et al. Thus, the method of microarc oxidation (MAO) allows one to obtain high-temperature modifications of aluminum oxides on the surface of aluminum alloys, which increases wear and corrosion resistance up to 20 times, contact endurance by $60-70 \%$, labour per part finishing is reduced in comparison with conventional technology of alumina deposition [8]. The use of SPD before MAO allows one to increase the hardness of the base and to lower the hardness gradient at the coating-base interface, which leads to reduced wear in this zone and the elimination of delamination during operation, as well as to a more uniform distribution of properties along the depth of the part surface layer [9].

In the process of electromechanical processing (EMP), a current of high strength and low voltage passes through the contact point of the deforming tool with the workpiece. Structural-phase transformations are carried out due to hardening, which occurs from heating of the contact spot and rapid removal of heat into the part, which can significantly improve the surface quality characteristics. Studies have shown high efficiency of EMP processing followed by finishing processing, which allows increasing the mechanical properties of SL at the EMP stage, and surface microgeometry at the finishing stage [10].

Rotary cutting allows, along with the removal of the allowance, to obtain SL hardening. The method is based on the replacement of traditional sliding friction between the workpiece and the cutting blade by rolling friction. Due to the increase in the length of the active section of the blade, the resistance of a rotary tool is 30-40 times higher than that of a conventional cutter [11]. At the same time, the way of joining it with SPD in one processing element is promising [12].

In order to expand technological capabilities, static-pulse processing of SPD is combined with the subsequent chemical-thermal treatment, in particular carbonization [13]. The 
widely used ultrasonic SPD in combination with thermal exposure allows you to control the structure and ultimately improve the SL mechanical properties [14]. The authors of [15], using a combination of continuous laser radiation and SPD, obtained in the SL the formation of a multilayer oriented microstructure.

One of the new and promising areas for the development of joined SPD methods is nano-structuring and the creation of an ultrafine-grained structure in SL due to intense plastic deformation $[16,17]$.

Whether applied simultaneously or sequentially, each of the methods makes it possible to strengthen this or other operational property. For example, the application of coatings (e.g. chromium) with subsequent SPD allows you to maintain the positive properties of the coating while reducing its roughness, porosity and increasing the fatigue strength by creating favorable compressive residual stresses.

In addition to ensuring high SL quality, the task of ensuring the accuracy and high productivity of the manufacturing process of machine parts also remains relevant.

\section{Materials and methods}

One of the simplest, most efficient and cost-effective methods is to join and combine SPD with machining by cutting, which, along with SL hardening, also provides dimensional accuracy, achieved mainly by cutting. In terms of sequence, such machining has 2 main schemes: "cutting - SPD", which is the most common and used both in size finishing and in hardening machining of various structural materials; "SPD - cutting", which is designed to facilitate the cutting process when machining difficult-to-process materials (high alloy steels and alloys) due to preliminary deformation. A feature of these and most other joint methods is the independent operation of the tools: despite their being joined in the same setup, the tools do not affect significantly each other during operation. So, with the joint machining by cutting and SPD, the cutter ensures dimensional accuracy of the part, and deforming tools increase quality and harden the machined surface. The geometric accuracy of joint machining as compared with combined turning and SPD is increased by $10-15 \%$ due to the fact that the deforming rollers, in addition to the rolling function, play the role of a movable lunette, thereby increasing dimensional accuracy by improving the working conditions of the cutter. For the same reason, the surface roughness after cutting decreases, this, in turn, affects the roughness and other properties of the surface layer of the part after SPD processing. The hardening effect after joint machining by cutting and SPD, ceteris paribus, is comparable to that effect obtained using combined cutting and SPD and is determined by the technological regimes and processing conditions of SPD.

The analysis shows that although the combined and joint methods of parts hardening with SPD have a significant number of advantages (improved accuracy, productivity, SL quality, etc.), they have several disadvantages, including:

- Wear of a blade (size-forming) tool is proportionally reflected in the size of the workpiece, and subsequent SPD processing does not solve this problem either in the case of elastic, or in the case of hard fixing;

- Low ability to correct the initial error of the workpiece during rolling in with rigidly fixed deforming tools and the absence thereof during their elastic fixing;

- Possibility to improve accuracy of joint SPD processing by increasing the stiffness of the fastening and tightness of deforming tools. However, variations in the allowance caused by the geometrical error of the workpiece, and the peculiar wave formation of the SPD processes significantly limit these possibilities;

- Lack of possibility to set various machining modes for cutting and deforming tools, and, as a consequence, the inability to ensure the optimal processing mode for each tool that provides the best surface properties. 
These shortcomings inhibit the use of combined and joint processing methods in the manufacture of parts with an accuracy of IT 7-8. The current situation can be changed by implementing a qualitatively different principle of tools integration.

The method of dimensional joint running-in (DJR) is based on the original scheme of the cutting and deforming tools interaction and is carried out by two or three spinning rollers with a diameter $D_{p}$ and a profile radius $R_{n p}$, rigidly adjusted to the size of the workpiece machining [20-21]. Of fundamental importance is the presence of a cutting plate in the wave formation zone, which is installed with an actual clearance $a_{\partial}$ between the cutting edge and the surface of the workpiece and which partially or completely removes the plastic wave of the metal with a height of $h_{b}$ (shaded area) (Fig. 1, a). The value of the actual rollers interference significantly exceeds those values adopted for the traditional SPD and can be set up over a wide range up to $h_{\partial}=0,05 . .1 \mathrm{~mm}$. However, the destruction of the surface, inevitable for such interference, does not occur due to the fact that the cutter removes part of the metal in the region of the apex of the plastic wave. An important condition for the normal course of the DJR process is the reliable removal of chips from the working area, thus, the cutting products are removed by cutting fluid which is supplied under pressure to the machining zone.

In machining by DJR, an asymmetric deformation zone $A B C_{l} C_{2} D E F G$ appears, which is characterized by contour lines of the front non-contact surface $A B C_{1}$, the surface in the area of contact with the cutter $C_{1} C_{2}$, the contact surface $C_{2} D E$, the rear noncontact surface $E F$, and also FGA line describing the boundary of the zone of plastic flow of metal. Due to deformation, metal particles along some current lines (for example, current lines 1 and 2, Fig. 1, a) are displaced in the wave formation zone into chips, and along a certain critical current line (LT 3) and below, they form the surface layer of the part. The initial state parameters that the metal particles had before entering the deformation zone (line $A G$ ) are transformed into those accumulated by the time they exit the OD (line $G F$ ).

The front surface of the machined part (MP) from the point the plastic wave originates to the apex of the roller has a total length $L$ consisting of a surface before the point of contact with the roller with length $l$ and a front contact surface of the roller with length $d$. Elasto-plastic metal reduction $\Delta$ behind the roller forms a rear surface $D E F$ with length $d_{l}$ (Fig. 1, a).

In general, the deformation zone that appears during the DJR machining is characterized by the same geometrical parameters as when machining by traditional SPD methods; the exception is the area in the plastic wave cutting zone.

When installing the cutting plate in such a way that it removes a metal layer of thickness $t$, the rollers are automatically set to a uniform value of $h_{\partial}=h_{p}$ (Fig. 1b). It is advisable to apply such a scheme when processing black surfaces, which, as a rule, have a large roughness and size and shape errors [18]. Structurally, the tools are rigidly connected and form a closed loop. The cutter is located between the rollers in a plane perpendicular to the axis of the part rotation and is offset relative to them to a certain angle (in Fig. 1, a, b, the cutter and the roller are conventionally brought into one plane).

The function of size formation in DJR is performed mainly by deforming tools ensuring the dimensional accuracy of IT 7-8 surface finish. Therefore, in the case of DJR in comparison with traditional joint cutting and SPD, the wear of the cutter affects the size of the part significantly less. Studies have shown that the DJR method allows you to obtain surface roughness $R a$ in the range of $0,12 \ldots 1,27$, the degree of hardening $\delta=12 \ldots 113 \%$ and the hardening depth $h$ up to $10 \mathrm{~mm}$ upon obtaining the favorable diagrams of compressive residual stresses.

Peculiarities of the interaction of cutting and deforming tools during DJR allow one to significantly increase the hardening effect and to accumulate large deformations without 
destroying the surface layer, as well as to increase the geometric accuracy of machining. The results of comparative calculations for a comparable SPD mode show that the cumulative shear strain level (CSSL) during DJR is approximately 4 times higher, and the plasticity reserve exhaustion level (PREL) increases only by 10 to $15 \%$ at large depths of plastic strain propagation. Electron microscopic studies of the machined surfaces have shown that in all cases of DJR machining, there is no destruction of the surface [19].

The components of the residual stress (RS) tensor at DJR have a distribution pattern similar to SPD, with the axial component having the highest negative (compressive) values for both methods. However, the depth of propagation significantly exceeds the similar values for SDP [20, 21].

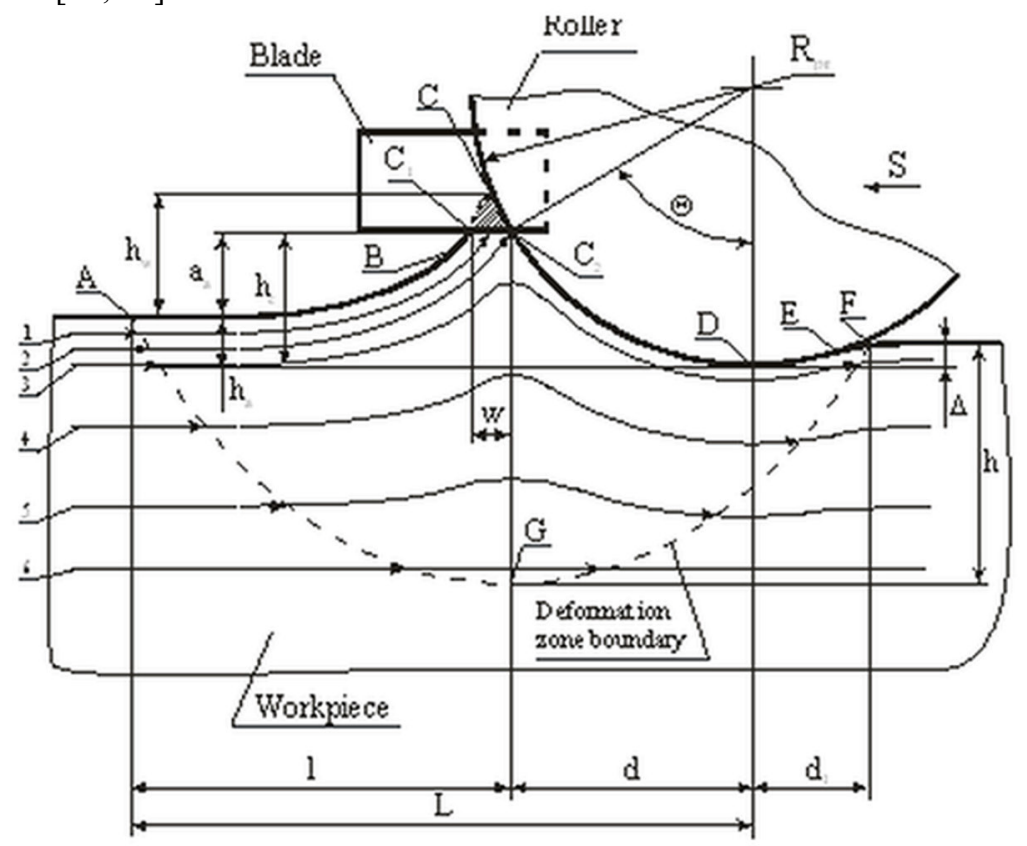

a)

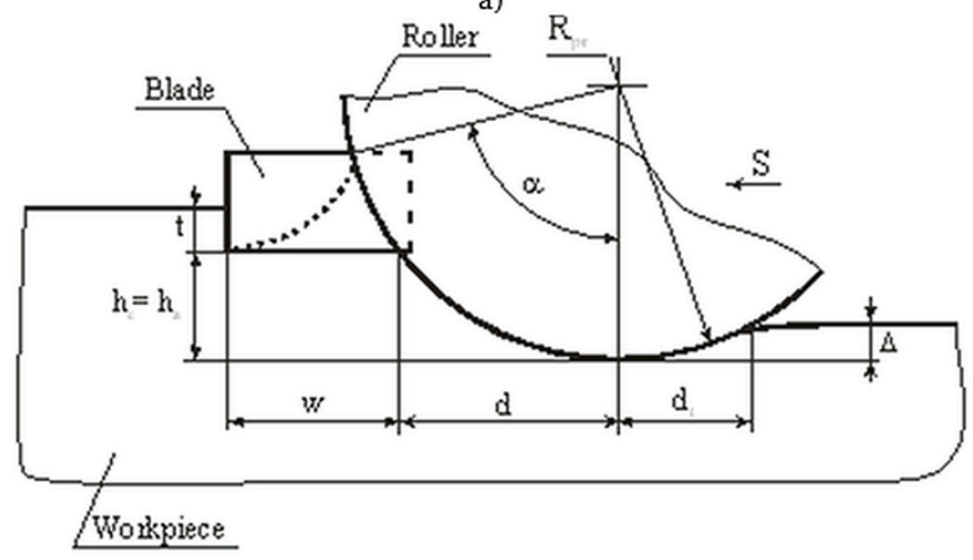

b)

Fig. 1. Scheme of deformation zone during machining by DJR: a) as per Scheme 1; b) as per Scheme 2. 


\section{Results and discussion}

As an example, the design and the technology of DJR machining method are discussed below. The workpiece (a rod) is an integral part of the lower jack, which is part of the mechanized complex. The rod is designed to transmit translational movement from the piston of the lower jack to the rear prop and it operates in long walls which are dust and gas hazardous, this leads to high requirements for the main working surface.

The analysis of the design and basic technology has shown the feasibility of replacing a number of turning and grinding operations with a single dimensional joint running-in operation.

The machine for dimensional joint running-in is created on the basis of a screw-cutting machine and carries out surface plastic deformation with large interference of deforming tools. Plastic wave cutting is carried out by a cutter equipped with a carbide plate. Cutting products are removed by cutting fluid supplied under pressure to the cutting zone. The rollers are adjusted to certain interference, set up to ensure the accuracy of the size of the runin part.

The main characteristics of the machine and machined products are given in Table 1 (Fig. 2).

Figures 3 to 5 present schemes of some assembly units of the machine. The device for DJR is mounted on the slide of the cross support of the screw-cutting machine and has housing 1 , three power heads, consisting of plungers 2 , pushers 3 , support rollers 4 (represented by needle bearings), clamping screws 5 and deforming rollers, which are divided into stand-alone rollers 6 and roller 7 joined with cutter 8 . The copy templets 9 are fixed with screws 10 on disk 11 , which is connected to hydraulic cylinders 12 by rods 13 . Springs 14 are connected with axles 15 and tension nuts 16 which rest on cover 17 . The roller diameter is smaller than the outer diameter of plunger 2, so the rollers together with the plungers go into the guide holes of the housing, which reduces its radial dimensions and decreases the plunger console.

Table 1. Key parameters of the machine and the workpiece.

\begin{tabular}{|l|c|}
\hline \multicolumn{1}{|c|}{ Description } & Value \\
\hline Workpiece dimensions, mm: & $45-100$ \\
\hline Diameter & Up to 1500 \\
\hline Length & $0.1-1.0$ \\
\hline Rollers interference fit, $\mathrm{mm}$ & $50-150$ \\
\hline Cutting speed, $\mathrm{m} / \mathrm{min}$ & $0.5-2.0$ \\
\hline Cutting depth, $\mathrm{mm}$ & IT (14-15)/IT (8-9) \\
\hline Accuracy, before/after DJR, $\boldsymbol{I T}$ & Not more than 0.4 \\
\hline Surface roughness $\boldsymbol{R}_{\boldsymbol{a}}, \boldsymbol{\mu m}$ & Up to 10.000 \\
\hline Force per 1 roller, N & Up to 10 \\
\hline Depth of hardened layer, mm & $2.5-3.0$ \\
\hline Durability increase, times & Electrohydraulic \\
\hline Control system & Semi-automatic \\
\hline Mode of operation & \\
\hline
\end{tabular}




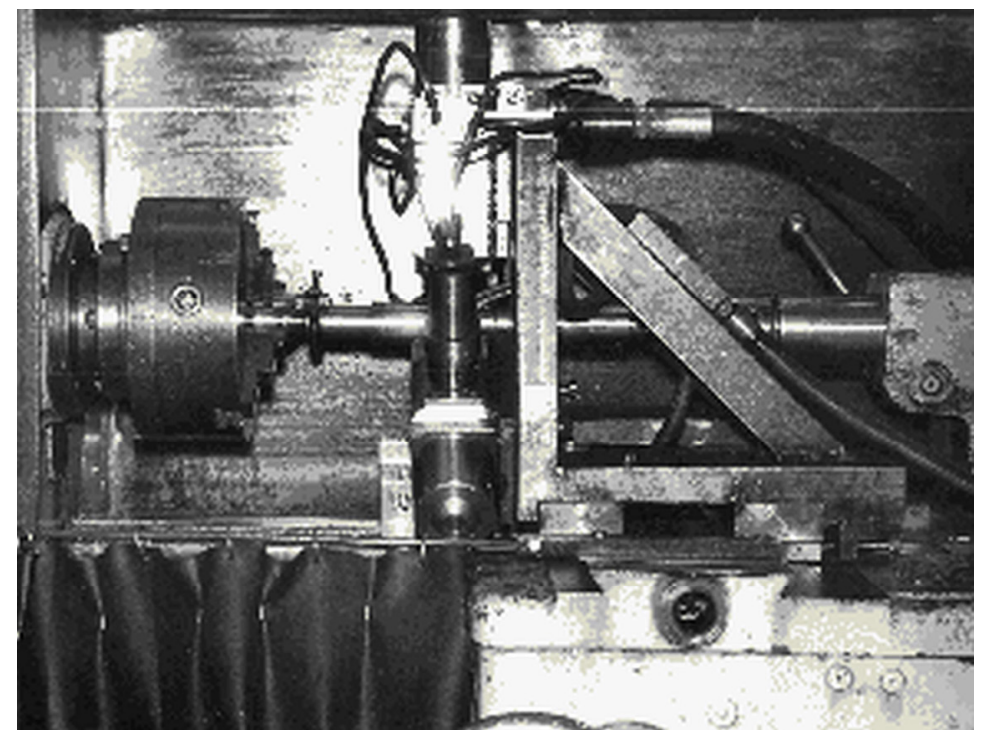

Fig. 2. General view of the operation zone of the machine for DJR.

Figure 4 shows the design diagram of roller 7 joined with cutter 8 . Roller 7 rotates on needle bearing 20 mated with axis 21 , which has a square cross-section at the cutter interface. The cutter consists of toolholder 22 equipped with a hard alloy plate 23 with mechanical fastening, chip breaker 24 , which is also a hard alloy plate, and clamping screw 25 . To adjust the rollers to the required size, the copy templets with the disk are brought into the working (extreme left) position. Screws 5 are loosened; plungers 2 with rollers are moved relative to pushers 3 to the required size, after which screws 5 are clamped. The device is operated; at the end of the machining, the hydraulic cylinders 12 divert disk 11 with copy templets 9 to the extreme right position. The heads are diverted from the machined surface by preloading to copy templets 9 by springs 14 . Cutter 8 setting to the required size is carried out by moving toolholder 22 relative to the part of the axis having a square in cross section, followed by fixing with screw 25 .

As an example, we have reviewed the efficiency calculation of an innovative project that envisages the introduction of a machine for dimensional joint running-in of the type of parts like "a rod" of a mine powered support manufactured at one of the enterprises of Kuzbass. The initial data for the investment project included: release program; number of staff; mass of the part and the workpiece; lathe retrofit costs; direct and total costs; inflation rates, etc.

Analysis of profit and loss (Income Statement), discounted cash flow (Cash Flow) and balance (Balance Sheet) has shown that the project will have been effective starting from the 2 nd year of implementation. In general, such production can be characterized as effective. Integral indicators with a calculation horizon of 5 years are: discount index $I=15 \%$; payback period $P B R=20$ месяиев (months); Profitability Index $P I=1,25$; Internal Rate of Return $I R R=65,8 \% ;$; Net Present Value $N P V=953769 \$$ USA. 


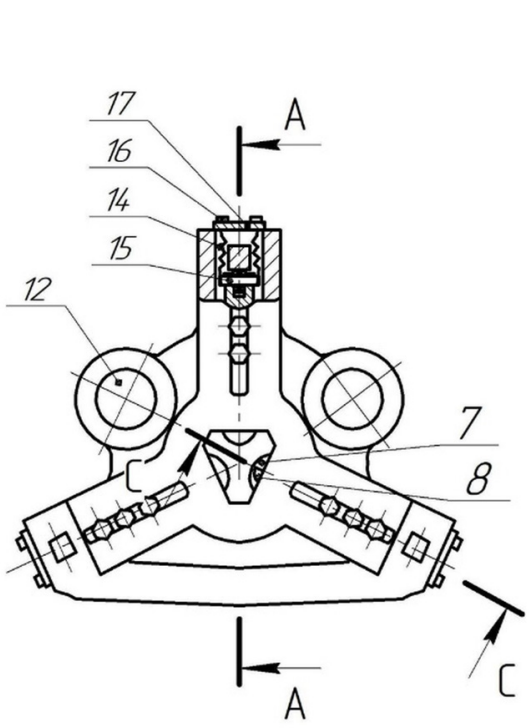

a)

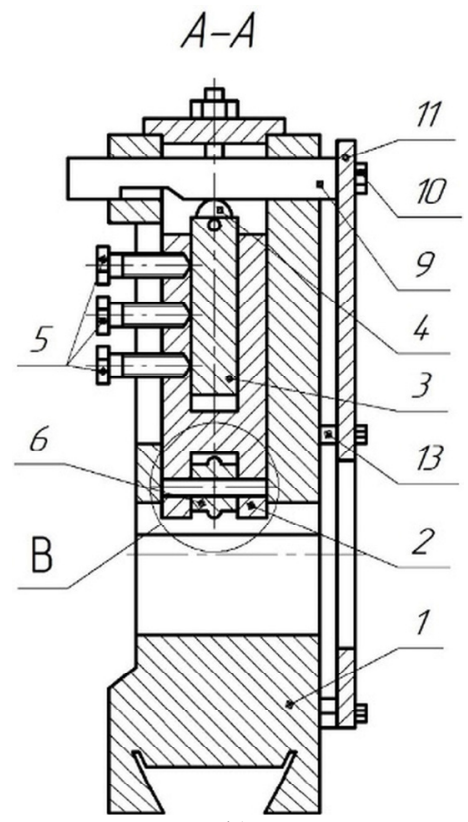

b)

Fig. 3. General scheme of the device for DJR: a) side view of the head stock; b) section A-A.

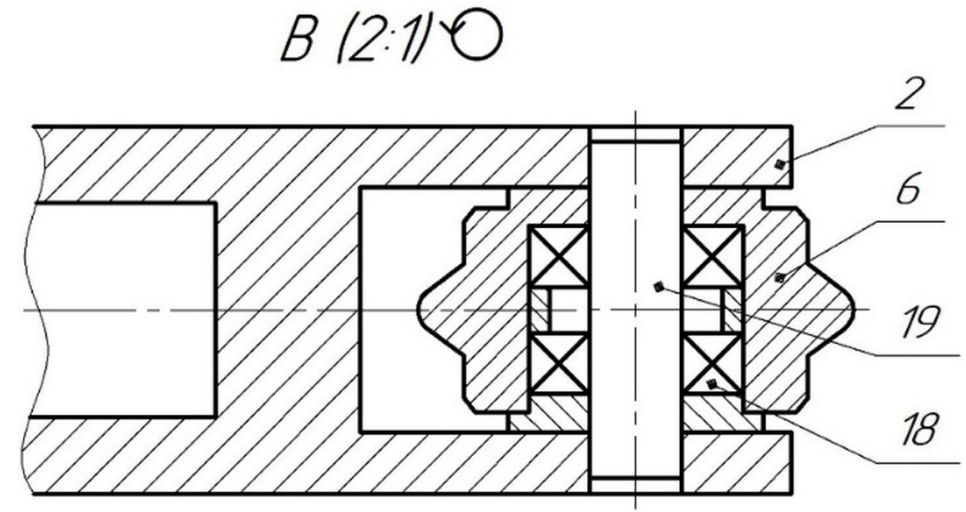

Fig. 4. Rollers fastening scheme (see Fig. 2, b). 


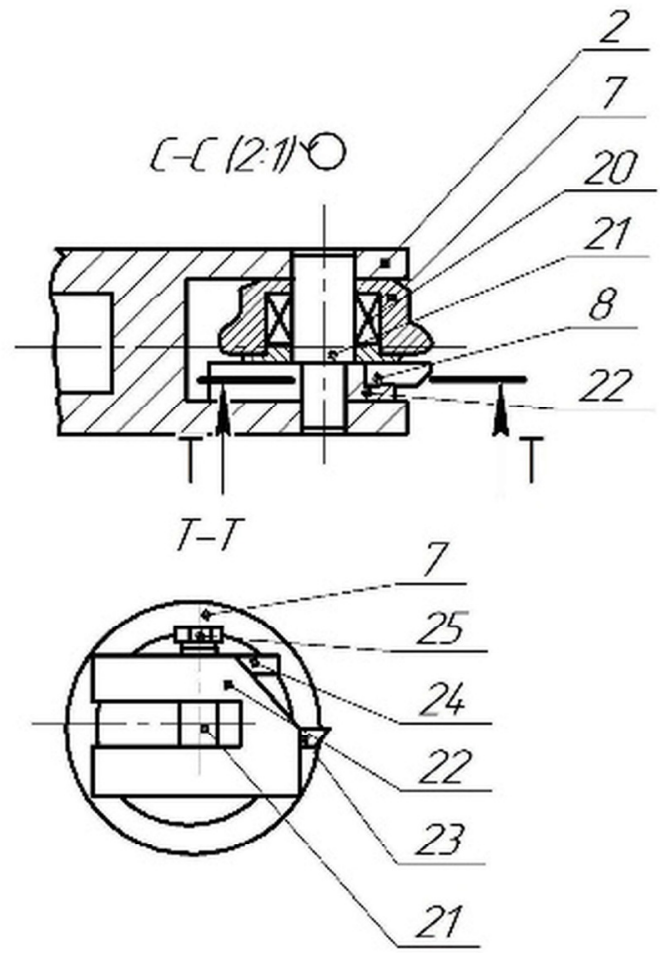

Fig. 5. Design scheme of roller unit joined with a cutter (see Fig. 1, a).

\section{Conclusions}

In the process of financial modeling of possible scenarios, the sensitivity of the project was analyzed by the net present value, the discounted payback period and the internal rate of return, which showed the project tolerance of changes in external environment. Based on the presented results of economic calculations, it has been concluded that the proposed investment (innovative) project can be implemented in the current economic situation, and the option adopted in the project is the most preferable.

Machines, devices and technologies have been tested at a number of engineering enterprises.

\section{References}

1. Y. Wang, X. Wu, X. Li, W. Wu, J. Gong, International Journal of Hydrogen Energy, 44, 7014 (2019)

2. A. S. Kilov, Russian engineering research, 32, 508 (2012) DOI: 10.3103/S1068798X12050085

3. A. V. Kirichek, S. V. Barinov, Applied mechanics and materials, 756, 65 (2015) DOI: 10.4028/www.scientific.net/AMM.756.65

4. V. V. Ivanov, N. S. Dontsov, A. V. Kirichek, Key engineering materials, 736, 105 (2017) DOI: 10.4028/www.scientific.net/KEM.736.105 
5. G. Bruno, M. Ceretti, E. Girardin, A. Giuliani, A. Manescu, Scripta materialia, 51, 999 (2004) DOI: 10.1016/j.scriptamat.2004.07.016

6. A. G. Radyuk, M. S. Balagushkin, K. A. Titlyanov, Steel in translation, 33, 59 (2003)

7. G. Ziętek, Z. Mróz, Mechanics of materials, 100, 154 (2016) DOI: 10.1016/j.mechmat.2016.06.004

8. V. M. Smelyansky, V. Yu. Blumenstein, E. P. Zemskova, Strengthening technologies and coatings, 7, 44 (2005)

9. V. M. Smelyansky, E. P. Zemskova, Strengthening technologies and coatings, 2, 32 (2005)

10. M. M. Matlin, N. G. Dudkina, A. N. Boldov, Strengthening technologies and coatings, 8, $44(2010)$

11. L. A. Gik, D. I. Shurygin, Russian engineering research, 29, 1040 (2009) DOI: 10.3103/S1068798X09100177

12. O. M. Schebrov, E. V. Preobrazhenskaya, Strengthening technologies and coatings, 8 , $41(2005)$

13. A. V. Kirichek, D. L. Soloviev, S. A. Silantiev, Science intensive technologies in mechanical engineering, 8:74, 30 (2017)

14. Kh. M. Rakhimyanov, Yu. V. Nikitin, Obrabotka metallov-metal working and material science, 1:54, 39 (2012)

15. V. F. Gubanov, M. A. Pesterev, Russian engineering research, 36, 571 (2016) DOI: $10.3103 / \mathrm{S} 1068798 \mathrm{X} 16070078$

16. M. V. Chukin, A. G. Korchunov, M. A. Polyakova, D. G. Emaleeva, Steel in translation, 40, 595 (2010) DOI: 10.3103/S0967091210060203

17. A. V. Kirichek, A. P. Kuzmenko, D. L. Soloviev, S. V. Barinov, A. Yu. Altukhov, S. A. Silantiev, A. N. Grechukhin, M. M. Than, M. B. Dobromyslov, Journal of Nanoand Electronic Physics, 7:4, 04023 (2015).

18. V. M. Smelyansky, Mekhanika uprochneniya detalej poverhnostnym plasticheskim deformirovaniem (Mashinostroenie, Moscow, 2002)

19. V. Yu. Blumenstein, M. S. Mahalov, Strengthening technologies and coatings, 2, 18 (2006)

20. V. Yu. Blumenstein, M. S. Mahalov, Obrabotka metallov-metal working and material science, 2:39, 15 (2008)

21. M. S. Mahalov, Obrabotka metallov-metal working and material science, 4:41, 17 (2008) 